\title{
A Refugee Rose of competencies and capabilities for mental healthcare of refugees
}

Kamaldeep Bhui

In this paper, I set out the challenges of care for refugees and suggest approaches to assessment and intervention. I discuss clinical interventions that can address the immediate concern of the clinician in a bio-psycho-social framework, and the value of considering eco-social and structural influences that can hinder recovery and perpetuate inequalities. Refugees face multiple adversities before, during and after escaping from life-threatening situations, political violence, torture and persecution. They present with complex health needs and encounter hostility from host countries and public services, which see their needs as an additional demand on the public purse. Regrettably, existing care practice and training of professionals do not often include skills for working across cultures, including cultural formulations and fair assessment, cultural adaptation of interventions, cultural competence and cultural consultation methods, including clinical ethnography and exploration of cultural identity and explanatory models. There are little data on effective and kind models of interpretation and translation. Care systems are rarely designed to fully address the needs of refugees. Health practitioners are not trained to address structural and institutional racism and discrimination, which leads to exclusion of the most marginalised, with little attention to social justice and fair processes as part of appropriate healthcare.

\section{Keywords}

Refugee; mental health; culture; ethnography; eco-social.

\section{Copyright and usage}

(c) The Author(s), 2022. Published by Cambridge University Press on behalf of the Royal college of Psychiatrists. This is an Open Access article, distributed under the terms of the Creative Commons Attribution licence (https://creativecommons.org/ licenses/by/4.0/), which permits unrestricted re-use, distribution, and reproduction in any medium, provided the original work is properly cited.
The United Nations Humanitarian Commission for Refugees (UNHCR) report ${ }^{1}$ of 2019 sets out the numbers of displaced persons globally, including refugees. There are 86.5 million people of concern to UNHCR, of which 4.1 million are asylum seekers, 20.4 million are refugees, 4.2 million are stateless persons, 5.7 million are returnees (refugees and internally displaced persons) and 43.5 million are internally displaced persons. Fifty-seven per cent of refugees come from Syria, Afghanistan and South Sudan. Thus, asylum seekers and refugees emerge from many distinct social and political contexts, from situations with decades and sometimes centuries of conflict affecting multiple generations. Sometimes refugees come from places facing famine, war or natural disasters; there are variable time periods between experienced persecution, torture or threat to life and the decision to flee; and then the duration of stay in the host country, and support and adversity during this period, will also shape the mental health consequences of earlier trauma and help-seeking. ${ }^{2}$ The premigration context from which refugees flee can also vary from relatively stable and resourced health and social systems with relatively safe and politically stable situations, to countries with extreme poverty and widespread health-related problems, all compounded by weak governance in public systems.

The humanitarian crisis facing refugees can be compounded by legal action in host countries that leads to precarity, marginalisation, criminalisation and victimisation. ${ }^{3}$ The diverse journeys people take to escape untenable situations in their countries of origin are themselves a threat to their lives; for example, hazardous sea crossings, paying intermediaries to escape and being criminalised, enslaved or subject to exploitation or sexual abuse. ${ }^{4-6}$ Children and unaccompanied minors are especially at risk of such hazards. Given the life-course risks of poor health (physical and mental), more life years lost and years of life lived with disability among people experiencing trauma and forced displacement, preventive interventions for young people might provide the greatest lifetime benefits. Thus, the response required is a multisystem bioecological set of actions, at individual, familial, community, school, institutional and policy levels, to benefit mental health and psychosocial well-being of refugee children. ${ }^{7}$ The greatest impacts are secured by multilevel interventions addressing interactions between ecological systems, proximal processes and the agency of the developing refugee child.

Refugees thus face multiple adversities and many potential journeys. There are marked variations in the post-migration experience in asylum countries, including social isolation, stigma, discrimination, gender violence, racism, criminalisation, unemployment and poverty. ${ }^{8-11}$ Any plans to respond to the health and social care needs of refugees must be cognisant of these multiple stories, from distinct countries, religious and cultural traditions, and the specific ecological and political niche in which their reason for fleeing evolved into a crisis. If people already suffer mental health problems at the time of fleeing, they will be more vulnerable to future mental health problems. Their ability to manage the stressors in their new environment with psychological flexibility may enable them to remain healthy and successful. ${ }^{12}$ Or, if their mental health is so compromised, they will struggle more than most if the support they experience does not nurture their talents and strengths. People of neurodiverse identities (autism, attention-deficit hyperactivity disorder, intellectual disability) experience adversity more intensely, and have greater difficulties overcoming the psychological and relational consequences, and therapeutic interventions need adaptation. ${ }^{5}$ Geographical mobility, housing instability and social isolation further compound poor health by exposure to more strains and hazards in the asylum-seeking journey. ${ }^{13,14}$

\section{Frameworks for assessment and intervention}

These complexities mandate that assessments of mental health and care and treatment plans consider personal narratives and meaningmaking, including attention to fractured moral frameworks, moral injury, social injustice and failures of state protections that are distressing, but not easily resolved through health systems. Furthermore, clinicians will need to attend to multiple social and cultural factors that influence the expression, management and 
meaning of evolving mental illness, as well as recovery from it. Specifically, people encountering mental health services should not be receiving care that is neglectful of their unique narratives and their location in intersectional positions, which are not anticipated by service designers and commissioners.

Refugees come from a range of national, cultural and religious contexts, requiring the clinician to engage with appropriate ways to assess psychopathology, and ascribe meaning to unusual or atypical symptoms of social or cultural distress that are easily pathologized and over-medicalised. ${ }^{3}$ Furthermore, from studies of cultural psychiatry, it is well-established that symptom expression varies by culture, and the interaction between doctor and patient influences the way people's distress is perceived, understood and responded to. As a consequence, the DSM-IV and DSM-5 recommend a cultural formulation interview, asking clinicians to pay attention to cultural identity and acculturation, explanatory models and health beliefs, cultural meanings and influences in the psychosocial environment, cultural perspectives on the clinicianpatient relationship and an overall judgement on the impact of culture on diagnosis. ${ }^{15}$ The Cultural Formulation Interview in the DSM-5 gives more guidance on the areas of enquiry, yet the training emphasises narrative methods to ensure the patient's specific story is embraced, heard, noted and built upon, ${ }^{16}$ as set out the following quote:

'.... basic interviewing skills extend to the art of conducting a person-centered, culturally informed evaluation .... flexible responses to the specifics of the person, problem, setting, and other elements of the interview ..... shaped by the identity and social position of both patient and clinician. ${ }^{16}$

These approaches have long been used in cultural psychiatry, yet never fully articulated and manualised for use in specific refugee populations. The DSM-IV and DSM-5 provide that opportunity, yet historically, the uptake is poor, given that biomedicine generally operates on universal principles assuming all peoples are physiologically and anatomically, and therefore socioculturally, sufficiently similar irrespective of cultural contexts. Health is affected not only by genes and biology, but also by the eco-social and psychosocial environment and social stressors over the life course. These adverse experiences (racism, poverty, isolation, unemployment) are manifestations of precarity, and drive poor health and inequalities.

Assessment and intervention for refugees must also embrace all we know from trauma studies about how adversity leads to poor health, weathering, inflammatory responses and shortened life expectancy. Medical liaison is therefore essential, requiring primary and specialist services to be integrated, and psychiatric and medical care to also be closely aligned. Adverse childhood experiences and traumatic experiences in adults both lead to physical and mental illnesses, and even shorter life expectancy. ${ }^{17-21}$ Thus, the clinical assessment, formulation, and care plan for asylum seekers and refugees has to reflect an understanding of the challenges faced by traumatised populations regarding post-traumatic symptoms and avoidance of reminders by the person suffering with poor health, as well as carers and service providers.

Refugees experience multiple social, political, ethical, legal and philosophical dilemmas when experiencing distress, and when they must make decisions about who can help them with the totality of their world view. Their perspectives cannot easily be mapped to discrete interventions that will be insensitive to wider aspects of their lived experience. The assessor and care system must also recognise historical antecedents to which the patient, or their parents, family and ancestors, may have been exposed; that is, the intergenerational transmission of trauma needs to be kept in mind. Although the bio-psycho-social approach is well established, there remain controversies in mental health settings about the balance of biological, social and psychological causes and related implications for therapeutics. Krieger proposes an eco-social approach that addresses these additional layers of history and contemporary adversity, as well as the biosocial interface. ${ }^{6,22}$ The assessor must be sensitive to the potential risk of multiple medical conditions and the way in which psychosocial adversity is embodied through physiological and psychological coping. Coping is not only about documenting discrete trauma events during the life course, but must be understood, and is conditioned by personal narratives and meanings assigned to the trauma and persecution, including historical narratives. More attention is needed around how structural sources of adversity, grounded in colonial histories, are sustained and affect marginalised people today.,

\section{Cultural competency}

Many countries have embraced cultural competency as an essential requirement to work with culturally and ethnically diverse populations, irrespective of refugee status, yet we lack large trials and evidenced models. ${ }^{23,24}$ Most specialist services are found in highincome countries seeking to respond to the needs of migrants and their descendants. Most of these services are not sustained in public-funded programmes, often relying on the charity and voluntary sector to address shortfalls. Diagnostic frameworks must be suited to specific regions around the world, although the relevance and validity of the frameworks are challenged not only for cultural fit, but also for overly reifying specific 'conditions' that may themselves be culturally constructed.

In a National Health Service (NHS) Trust in East London, I evolved the cultural consultation model ${ }^{25}$ originally developed at McGill University, ${ }^{26}$ using aspects of the cultural formulation, incorporating the Barts Explanatory Model Interview and undertaking in-depth investigations of the narratives of both the referring clinicians, teams and organisations, as well as the patients. This approach showed that conflicts between patient and services were the product of a complex interplay of an ill-fitting service narratives and the actual patient experience. Although developed for a specific NHS context, within a UK-based system of commissioning and provision, the principles are relevant for all societies where cultural complexity may confound optimal assessment of mental health status and the allocation effective care pathways and interventions. There are core skills for clinicians that can be transported and adapted for local populations, but the services will be constrained by national political contexts and sentiments toward the framing of identity, ethnicity and race. ${ }^{27}$ The specific form in which cultural consultation is delivered varies between countries, and the local pathways and available interventions will also depend on resources from public services or from the charity sector. Thus, understanding the local assets and resources is a necessary part of offering such a service. Indeed, cultural competence and measures to improve services for migrants have been focused mostly in high-income countries, perhaps because of hostile attitudes toward migrants or the adoption of institutional frameworks for care provision (from the high-income countries) that do not fully attend to cultural diversity. ${ }^{28}$ The lack of resources devoted to mental health is part of the challenge in low- and middle-income countries, and so models of care will need to be realistic, sustainable and locally designed; for example, lay and peer workers can deliver psychological interventions with good effect, at much less cost. ${ }^{29}$ Clearly, this helps overcome language barriers to some extent, and reduces social isolation. ${ }^{30}$

Ethnography is part of the approach. This originates from anthropological research methods that were adapted into clinical 
practice. The value of this is that ethnography assumes nothing about the patient and locates the initial conversation as one of discovering the patient's world view, beliefs and positionality, rather than focusing on the often pressing administrative and clinical checklists. Furthermore, ethnography captures narratives of patients' sources of suffering in an authentic manner, intact, and with all the complex interplays between intersectional webs of causations that often evade the biomedical and psychiatric gaze. The clinical task can over-prioritise the pressing pursuit of psychopathology and a formulation, drawing on familiar and trusted scripts to match - as quickly as possible - which therapeutic offers might be helpful. Thus clinical ethnography is a tool for assessment and understanding, and necessarily slows down this process to encourage careful reflection; it addresses not only the individual embodied experience of distress, but also the social nexus within which it arises, the beliefs and vocabularies of the patient and her kinship system, and the intersectional and social positionality of the person seeking help and the clinician. ${ }^{31,32}$ Ethnography and cultural consultation methods can also interrogate organisational practices that are institutionalised and unnoticed, ${ }^{33,34}$ yet these can give rise to the neglect of racism and the complex needs of marginalised groups; the risk is that such practices are silent on the coercive and criminalising responses from the state and institutions, when these interact with vulnerable populations. ${ }^{33,35}$ For example, if racism is part of the lived experience of those seeking help, and clinicians do not recognise it or ask about it, this reinforces a lack of connection with the patient and can lead to alienation and isolation. Similarly, if there are linguistic barriers, and the clinician is not skilled in working with interpreters, or the provider organisation or national policies do condone these or provide funds for such interpreting services, ${ }^{36}$ those with diverse linguistic needs will receive an inferior service. Communication is compromised, and the risks of miscommunication and mistakes in the classification of diagnostic labels and care pathways is inevitable and may lead to coercive care and unhelpful interventions with associated adverse consequences, and the patient may feel rejected and become avoidant of an unhelpful or an authoritarian approach to care. $^{25,26,37}$

\section{Innovations for eco-social narrative interventions}

The notion of eco-social and structural interventions may seem far removed from the daily work of psychiatrists, and mental health professionals generally. However, when facing traumatised refugees, the trauma narrative testimony and the medicalisation of distress become a gateway to legislative endorsement of refugee status, forcing a narrowed lens. I have outlined why a broader perspective is essential to engage people in an authentic recovery process. There is now interest in more complex trauma, and cognitive-behavioural therapy treatments are recognised to be of value for traumatised adults and children, albeit requiring cultural adaptation of philosophical, technical, theoretical and practical aspects of therapy. ${ }^{38,39}$ Narrative exposure therapy is a promising intervention developed in low-resource settings, and even amid sustained conflict, seeking to process 'hot' memories that trigger fear circuits, and render them as stable as 'cold' memories. ${ }^{40}$ The approach uses creative methods, such as using flowers and stones to indicate hot and cold memories, and placing them along a piece of string or rope (representing the timeline/age of the person); such approaches show promise with young people and adults, with systematic review evidence showing moderate effect sizes. ${ }^{41,42}$

A review of quasi-experimental and qualitative studies ${ }^{43}$ found the evidence base for interventions in refugees to be generally poor, but recommended that mental health interventions must address immediate needs and concerns before focusing on past traumas, and consider social groups, group therapy and building a social network in conjunction with pharmacotherapy and individual counselling. The ordering of interventions should be driven by the narrative emphasis given by the patient for immediate concerns, and only then can the clinician's judgement of priorities be carefully explained, negotiated and located within the patient's preferred approach to recovery.

Another approach to developing relevant interventions is to engage with communities in intervention development and delivery. Many models of research and community support are adopting community-based participatory processes, applying strength-based interventions. For example, the Refugee Wellbeing Project ${ }^{44}$ includes the following elements/aims: refugee families and undergraduate advocates paired for 6 months; increase ability to navigate new communities; improve access to community resources; enhance meaningful social roles by valuing cultures, experiences and knowledge; reduce social isolation; and increase community responsiveness to refugees. The project intervention includes learning circles to create connections, improve communication and linguistic skills, reduce social injustice, provide empowerment and agency, leading to less anxiety and depression among refugees. ${ }^{44}$

The silos within services fail to recognise the interactions and interfaces of history, the social and cultural world, cognitions and beliefs, morals and political ideologies, and biological vulnerabilities and responses. Indeed, the current health systems are designed to be efficient for care provision and the provider, and rarely to meet the complex experiences of refugees with mental health problems. Narratives in research and clinical practice also reminds all of what is at stake, and emotionally and behaviourally motivate clinicians and policy makers to show courage and address the wider systemic failing of care services. ${ }^{45,46}$ The 'Refugee Rose' (Fig. 1) shows the complex influences and bodies of scholarship that need to be aligned for effective assessment, with implications for clinical training, continuing professional development and self-care. Providing assessments and care for refugee populations with multiple adversities and traumas challenges systems of care and our own abilities to empathise, reflect, learn and adapt our interventions and service models. This is a demanding task and vicarious secondary traumatisation of carers and professionals is well established, which can lead to pessimism, depersonalisation, feelings of powerlessness and therapeutic nihilism, especially where there are complex comorbidities such as depression and post-traumatic symptoms, or marked and sustained psychosocial adversity, such that our efforts seem futile until the structural determinants of distress are resolved. In psychodynamic terms, the carer and professional must understand the transference and countertransference (feelings-fears-experience-responses-enactments), and the power of projective identifications, through which the clinician identifies deeply with the unbearable and projected aspects of the patient's internal world. Thus, the clinician must secure appropriate opportunities for review, reflection, supervision and advice. The Cultural Consultation Service ran in East London for 18 months and took 900 referrals. As part of the work of the service, my team established a monthly Cultural Consultation Club, which served exactly the function of giving clinicians and practitioners a creative space and opportunity to discuss aspects of care that were not easily raised in increasingly pressured and resource strained public services. The principles were adopted from the world of cultural psychiatry, using ethnography and thick description, anthropological and social science perspectives, and bringing theory and frameworks of practice together to expose highly structured and often inflexible care pathways. There are good examples of narrative and person-centred approaches to assessment and intervention that also provide social support and care to the most 
Eco-social: history,

ecology, environment

social \& structural

determinants

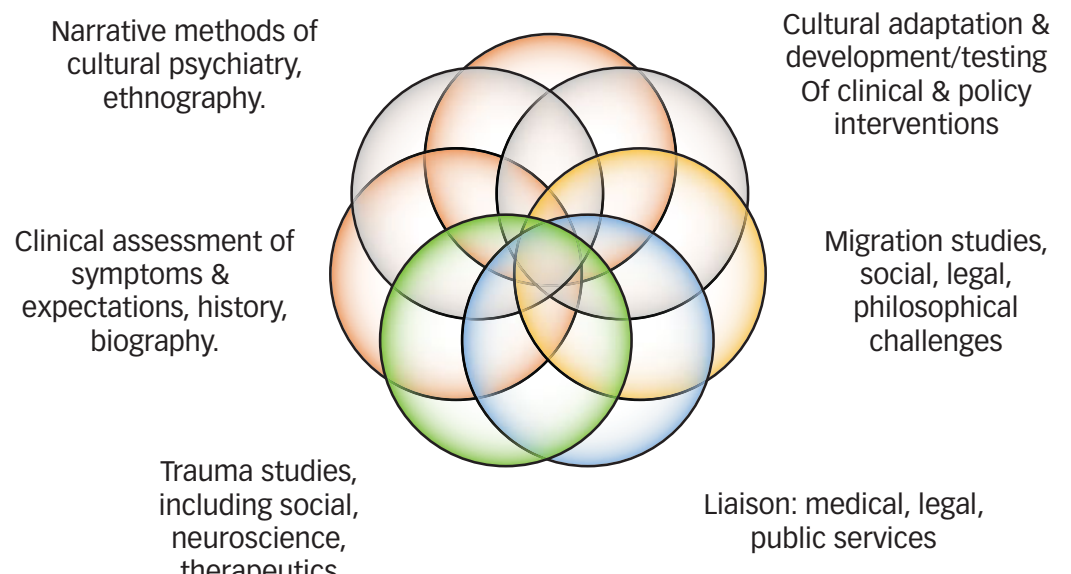

Fig. 1 Refugee rose of competencies and capabilities for mental healthcare.

marginalised. Such interventions necessarily must work at the complex intersections of multiple adversities, socioeconomic adversity, and isolation and victimisation. ${ }^{47,48}$ Only through such innovations will we address the complexity of need among those facing historical and contemporary adversity while continuing to live in positions of marginalisation and exclusion. Unpacking the institutional and societal drivers of such intersectional inequalities, including discrimination and racism, have been exposed by the recent COVID0-19 pandemic, ${ }^{49,50}$ showing that social and health systems reforms are needed. Ultimately, political commitment and the organised efforts of society can provide innovation and sustainable solutions, albeit research and practice must continue to be grounded in broad-based evidence and counter institutional and historical forces that sustain hostile and unevidenced policies and practices.

Kamaldeep Bhui (D), Department of Psychiatry and Nuffield Department of Primary Care Health Sciences, University of Oxford, UK; East London NHS Foundation Trust, UK oxford Health NHS Foundation Trust, UK; and World Psychiatric Association Collaborating Centre in Research, Training, Policy and Practice, UK

Correspondence: Kamaldeep Bhui. Email: kam.bhui@psych.ox.ac.uk

First received 16 May 2021, final revision 31 Dec 2021, accepted 4 Jan 2022

\section{Funding}

This research received no specific grant from any funding agency, commercial or not-for-profit sectors.

\section{Declaration of interest}

K.B. is Editor-in-Chief of BJPsych (not BJPsych Open) and College Editor, and has not played any part in the processing or decision-making of this paper.

\section{References}

1 United Nations High Commissioner for Refugees. Global Report 2019. UNHCR, 2019 (https://reporting.unhcr.org/sites/default/files/gr2019/pdf/GR2019_English_Full_ lowres.pdf\#_ga=2.177267301.1787306353.1643383569-67090188.1614254991).

2 Khan S, Haque S. Trauma, mental health, and everyday functioning among Rohingya refugee people living in short- and long-term resettlements. Soc Psychiatry Psychiatr Epidemiol 2021; 56(3): 497-512.
3 Kronick R, Jarvis GE, Kirmayer L. Refugee mental health and human rights: a challenge for global mental health. Transcult Psychiatry 2021; 58(2): 147-56.

4 Brodda Jansen G. Two patient cases illustrating the importance of addressing physical and mental trauma as a cause of pain in refugee women. Front Sociol 2020; 5: 12.

5 Frounfelker RL, Miconi D, Farrar J, Brooks MA, Rousseau C, Betancourt TS. Mental health of refugee children and youth: epidemiology, interventions, and future directions. Annu Rev Public Health 2020; 41: 159-76.

6 Krieger N. Methods for the scientific study of discrimination and health: an ecosocial approach. Am J Public Health 2012; 102(5): 936-44.

7 Arakelyan S, Ager A. Annual research review: a multilevel bioecological analysis of factors influencing the mental health and psychosocial well-being of refugee children. J Child Psychol Psychiatry 2021; 62(5): 484-509.

8 Di Thiene D, Helgesson M, Rahman S, Alexanderson K, Tiihonen J, La Torre G, et al. Risk of labour market marginalisation among young refugees and nonrefugee migrants with common mental disorders. Soc Psychiatry Psychiatr Epidemiol 2021; 56(6): 1025-34.

9 Hossain M, Pearson R, McAlpine A, Bacchus L, Muuo SW, Muthuri SK, et al. Disability, violence, and mental health among Somali refugee women in a humanitarian setting. Glob Ment Health (Camb) 2020; 7: e30.

10 Hess JM, Isakson BL, Amer S, Ndaheba E, Baca B, Goodkind JR. Refugee mental health and healing: understanding the impact of policies of rapid economic selfsufficiency and the importance of meaningful work. J Int Migr Integr 2019; 20(3): 769-86.

11 Nickerson A, Byrow Y, Pajak R, McMahon T, Bryant RA, Christensen H, et al. 'Tell your story': a randomized controlled trial of an online intervention to reduce mental health stigma and increase help-seeking in refugee men with posttraumatic stress. Psychol Med 2020; 50(5): 781-92.

12 Kashyap S, Keegan D, Liddell BJ, Thomson T, Nickerson A. An interaction model of environmental and psychological factors influencing refugee mental health. J Trauma Stress 2021; 34(1): 257-66.

13 Bhui K, Abdi A, Abdi M, Pereira S, Dualeh M, Robertson D, et al. Traumatic events, migration characteristics and psychiatric symptoms among Somali refugees-preliminary communication. SOC Psychiatry Psychiatr Epidemiol 2003; 38(1): 35-43.

14 Warfa N, Bhui K, Craig T, Curtis S, Mohamud S, Stansfeld S, et al. Post-migration geographical mobility, mental health and health service utilisation among Somali refugees in the UK: a qualitative study. Health Place 2006; 12(4): 503-15.

15 Lewis-Fernandez R, Diaz N. The cultural formulation: a method for assessing cultural factors affecting the clinical encounter. Psychiatr Q 2002; 73(4): 271-95.

16 Lewis-Fernández R, Aggarwal NK, Kirmayer LJ. The Cultural Formulation Interview: progress to date and future directions. Transcult Psychiatry 2020; 57(4): 487-96.

17 Hughes K, Ford K, Kadel R, Sharp CA, Bellis MA. Health and financial burden of adverse childhood experiences in England and Wales: a combined primary data study of five surveys. BMJ Open 2020; 10(6): e036374. 
18 Bellis MA, Hughes K, Ford K, Ramos Rodriguez G, Sethi D, Passmore J. Life course health consequences and associated annual costs of adverse childhood experiences across Europe and North America: a systematic review and metaanalysis. Lancet Public Health 2019; 4(10): e517-28.

19 Hollander AC, Bruce D, Ekberg J, Burstrom B, Borrell C, Ekblad S. Longitudinal study of mortality among refugees in Sweden. Int J Epidemiol 2012; 41(4): 1153-61.

20 Hollander AC. Social inequalities in mental health and mortality among refugees and other immigrants to Sweden-epidemiological studies of register data. Glob Health Action 2013; 6: 21059

21 Muller LRF, Buter KP, Rosner R, Unterhitzenberger J. Mental health and associated stress factors in accompanied and unaccompanied refugee minors resettled in Germany: a cross-sectional study. Child Adolesc Psychiatry Ment Health 2019; 13: 8.

22 Kirmayer LJ. Embracing uncertainty as a path to competence: cultural safety empathy, and alterity in clinical training. Cult Med Psychiatry 2013; 37(2): 365-72.

23 Bhui K, Warfa N, Edonya P, McKenzie K, Bhugra D. Cultural competence in mental health care: a review of model evaluations. BMC Health Serv Res 2007; 7: 15

24 Kirmayer LJ. Rethinking cultural competence. Transcult Psychiatry 2012; 49(2): 149-64.

25 Bhui KS, Owiti JA, Palinski A, Ascoli M, De Jongh B, Archer J, et al. A cultural consultation service in East London: experiences and outcomes from implementation of an innovative service. Int Rev Psychiatry 2015; 27(1): 11-22.

26 Kirmayer LJ, Groleau D, Guzder J, Blake C, Jarvis E. Cultural consultation: a model of mental health service for multicultural societies. Can J Psychiatry 2003; 48(3): 145-53.

27 Jarvis GE, Larchanche S, Bennegadi R, Ascoli M, Bhui KS, Kirmayer LJ. Cultural consultation in context: a comparison of the framing of identity during intake at services in Montreal, London, and Paris. Cult Med Psychiatry 2020; 44(3): 433-55.

28 Pocock NS, Chan Z, Loganathan T, Suphanchaimat R, Kosiyaporn H, Allotey P, et al. Moving towards culturally competent health systems for migrants? Applying systems thinking in a qualitative study in Malaysia and Thailand PLOS One 2020; 15(4): e0231154.

29 Patel V, Chowdhary N, Rahman A, Verdeli H. Improving access to psychological treatments: lessons from developing countries. Behav Res Ther 2011; 49(9): 523-28.

30 World Health Organization (WHO). Mental Health Promotion and Mental Health Care in Refugees and Migrants. WHO, 2018 (https://www.euro.who.int/_data/ assets/pdf_file/0004/386563/mental-health-eng.pdf).

31 Owiti JA, Ajaz A, Ascoli M, de Jongh B, Palinski A, Bhui KS. Cultural consultation as a model for training multidisciplinary mental healthcare professionals in cultural competence skills: preliminary results. J Psychiatr Ment Health Nurs 2014; 21(9): 814-26.

32 Bhui K, Dein S, Pope C. Clinical ethnography in severe mental illness: a clinical method to tackle social determinants and structural racism in personalised care. BJPsych Open 2021; 7(3): e78.

33 Adamson J, Warfa N, Bhui K. A case study of organisational cultural competence in mental healthcare. BMC Health Serv Res 2011; 11: 218
34 Archival teaching museum-London psychiatric hospital. Can Psychiatr Assoc J 1972; 17(1): 78

35 Bhui K, Ascoli M, Nuamh O. The place of race and racism in cultural competence: what can we learn from the English experience about the narratives of evidence and argument? Transcult Psychiatry 2012; 49(2): 185-205.

36 Ingleby D. Migration and health. Pan Eur Netw Gov 2013; 8: 60-1.

37 Seeleman C, Essink-Bot ML, Stronks K, Ingleby D. How should health service organizations respond to diversity? A content analysis of six approaches. BMC Health Serv Res 2015; 15: 510.

38 Hinton $D E$, Pham $T$, Tran $M$, Safren SA, Otto MW, Pollack MH. CBT for Vietnamese refugees with treatment-resistant PTSD and panic attacks: a pilot study. J Trauma Stress 2004; 17(5): 429-33.

39 Hinton DE, Rivera El, Hofmann SG, Barlow DH, Otto MW. Adapting CBT for traumatized refugees and ethnic minority patients: examples from culturally adapted CBT (CA-CBT). Transcult Psychiatry 2012; 49(2): 340-65.

40 Robjant $\mathrm{K}$, Fazel $\mathrm{M}$. The emerging evidence for narrative exposure therapy: a review. Clin Psychol Rev 2010; 30(8): 1030-9.

41 Fazel M, Stratford HJ, Rowsell E, Chan C, Griffiths H, Robjant K. Five applications of narrative exposure therapy for children and adolescents presenting with post-traumatic stress disorders. Front Psychiatry 2020; 11: 19.

42 Siehl S, Robjant K, Crombach A. Systematic review and meta-analyses of the long-term efficacy of narrative exposure therapy for adults, children and perpetrators. Psychother Res 2021; 31(6): 695-710.

43 Peterson C, Poudel-Tandukar K, Sanger K, Jacelon CS. Improving mental health in refugee populations: a review of intervention studies conducted in the United States. Issues Ment Health Nurs 2020; 41(4): 271-82.

44 Goodkind JR, Bybee D, Hess JM, Amer S, Ndayisenga M, Greene RN, et al Randomized controlled trial of a multilevel intervention to address social determinants of refugee mental health. Am J Community Psychol 2020; 65(3-4): 272-89.

45 Greenhalgh T, Hurwitz B. Narrative based medicine: why study narrative? BMJ 1999; 318(7175): 48-50.

46 Greenhalgh T, Russell J, Swinglehurst D. Narrative methods in quality improvement research. Qual Saf Health Care 2005; 14(6): 443-9.

47 Burgess RA, Jeske N, Rasool S, Ahmad A, Kydd A, Ncube Mlilo N. Exploring the impact of a complex intervention for women with depression in contexts of adversity: a pilot feasibility study of COURRAGE-plus in South Africa. Int J Soc Psychiatry [Epub ahead of print] 15 Apr 2021. Available from: https://doi.org/ 10.1177/00207640211010203

48 Biracyaza E, Habimana S. Contribution of community-based sociotherapy interventions for the psychological well-being of Rwandan youths born to genocide perpetrators and survivors: analysis of the stories telling of a sociotherapy approach. BMC Psychol 2020; 8: 102.

49 Kapilashrami A, Bhui K. Mental health and COVID-19: is the virus racist? $\mathrm{Br} \mathrm{J}$ Psychiatry 2020; 217(2): 405-7.

50 Bhui K. Ethnic inequalities in health: the interplay of racism and COVID-19 in syndemics. EClinicalMedicine 2021; 36: 100953.

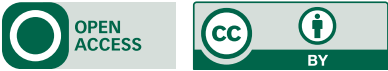

